\title{
Gradhiva
}

\section{Roland Vilella, La Sentinelle de fer : mémoires du bagne de Nosy Lava (Madagascar).}

Paris, Plon, coll. « Terre humaine », 2016

\section{Frédéric Keck}

\section{(2) OpenEdition}

\section{Journals}

Édition électronique

URL : http://journals.openedition.org/gradhiva/3349

DOI : 10.4000/gradhiva.3349

ISSN : 1760-849X

\section{Éditeur}

Musée du quai Branly Jacques Chirac

Édition imprimée

Date de publication : 31 mai 2017

Pagination : 263-264

ISBN : 978-2-35744-095-1

ISSN : 0764-8928

\section{Référence électronique}

Frédéric Keck, "Roland Vilella, La Sentinelle de fer : mémoires du bagne de Nosy Lava (Madagascar).», Gradhiva [En ligne], 25 | 2017, mis en ligne le 31 mai 2017, consulté le 24 septembre 2020. URL : http:// journals.openedition.org/gradhiva/3349; DOI : https://doi.org/10.4000/gradhiva.3349

Ce document a été généré automatiquement le 24 septembre 2020.

(c) musée du quai Branly 


\title{
Roland Vilella, La Sentinelle de fer :
} mémoires du bagne de Nosy Lava (Madagascar).

\author{
Paris, Plon, coll. « Terre humaine », 2016
}

Frédéric Keck

\section{RÉFÉRENCE}

Roland Vilella, La Sentinelle de fer : mémoires du bagne de Nosy Lava (Madagascar). Paris, Plon, coll. «Terre humaine », 2016, 288 p. 


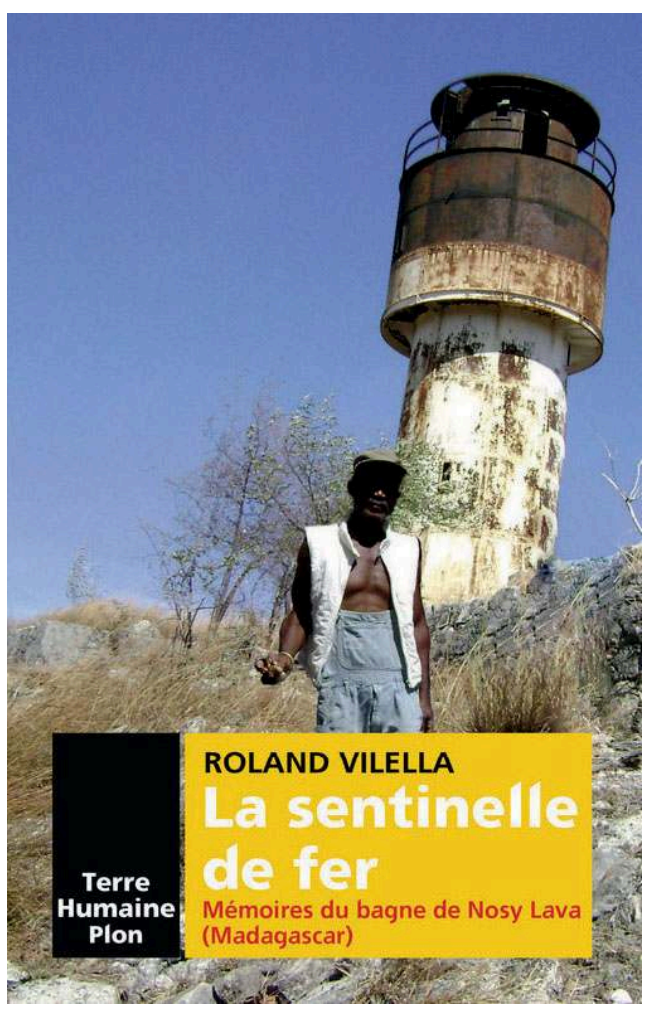

1 La collection « Terre humaine » des éditions Plon, fondée par Jean Malaurie en 1955, est dirigée depuis janvier 2015 par Jean-Christophe Rufin, médecin, diplomate et écrivain. Elle poursuit une prestigieuse série de livres à la croisée de l'ethnographie et de la littérature, de l'étude et du témoignage ${ }^{1}$, avec un nouveau comité éditorial et une nouvelle maquette. Le livre publié par Roland Vilella marque bien ce renouvellement dans la continuité.

Roland Vilella est un navigateur qui voyage depuis vingt ans dans les eaux de l'océan Indien. Entre 2004 et 2010, il a accosté à plusieurs reprises sur l'île de Nosy Lava, au nord-ouest de Madagascar. Il y a rencontré des bagnards enfermés à vie dans ce qui ressemble à un enfer sur une île apparemment paradisiaque. Des hommes, emprisonnés pour des meurtres sanglants ou de simples vols de bovins, sont soumis quotidiennement à la cruauté des gardes et à l'arbitraire des directeurs qui s'y succèdent. Le navigateur se fait le témoin des récits hallucinés de ces hommes ayant assisté à des scènes d'une violence inouïe et qui peuvent tous être décrits comme des survivants.

Le livre commence sur une scène à la limite de l'insoutenable: les prisonniers qui arrivent au bagne en bateau sont soumis au rituel du « baptême ", battus par des gardes hurlant, assoiffés de sang. Ceux qui y survivent doivent effectuer des travaux absurdes, comme le transport de pierres, à peine atténués par des tâches de jardinage ou de navigation. L'auteur, délicatement entré sur scène, recueille et confirme les témoignages, puis enquête dans les archives du bagne. L'armée française l'a ouvert pour les prisonniers politiques après l'insurrection de 1947 puis fermé en 1957. L'État malgache le rouvrit pour les prisonniers de droit commun dans les années 1970.

Lorsque Roland Vilella arrive à Nosy Lava en 2004, le rituel du «baptême » et les cycles de violence quotidienne qu'il engendre ont été interdits depuis trois ans. Mais un témoin privilégié, Albert Abolaza, lui suggère d'écrire l'histoire du bagne. Il s'est lui- 
même évadé, avec un complice en 1983, du bagne où il était emprisonné pour meurtre depuis plusieurs années, et il y revint de son plein gré après une nuit de liberté. Le récit des traitements qui lui sont imposés à son retour (p. 77-133) confirme le sentiment d'une extrême violence collective, perçue par un seul individu qui s'attend à en mourir.

5 Un autre récit vient faire basculer l'histoire du bagne (p. 133-155). Claude Randriamanga, gardien du bagne, est pris de remords après que sa femme et sa fille se détournent de lui en voyant le sang d'un prisonnier qu'il a tué à coups de noix de coco. Son départ (il s'installe à Mahajanga où il occupe différents emplois avant d'être assassiné par d'anciens bagnards) suscite une première remise en question de l'ordre carcéral. En 1985, le président du tribunal d'Analalava, Randriamialison, mène une enquête sur les procédures du bagne. Il sera dessaisi de l'affaire et muté à Antanarivo, tandis que le directeur du bagne, Bakamen, est nommé à la prison d'Analalava. Roland Vilella le retrouve vingt ans plus tard et confirme avec lui, à mots couverts, les accusations qu'il avait portées. Les directeurs qui se succèdent ensuite limitent en partie le déchaînement de la cruauté, même si la violence sexuelle continue de s'exercer, avec un taux de mortalité de $20 \%$ par an. Le dernier meurtre public, celui de Kamara en 2001, suscita une mobilisation de la communauté musulmane et l'arrestation de deux gardiens.

Roland Vilella, soucieux de se tenir respectueusement au niveau des témoins qu'il fait parler, ne peut s'empêcher de poser finalement la question: "Pourquoi, à de rares exceptions près [...], la situation faite aux prisonniers n'a-t-elle jamais été dénoncée publiquement avec des relais suffisamment puissants pour contraindre l'État à mettre un terme à des méthodes aussi barbares?» (p. 230) Une question qui reste sans réponse. Albert, son principal témoin libéré en 2008, reste à Nosy Lava où il meurt mystérieusement un an plus tard. Dans une discussion avec un gardien qui s'indignait en 1982 du traitement fait aux militants de l'ANC par le régime d'apartheid en Afrique du Sud, Albert se contente d'affirmer : «Je trouve normal que les Blancs tuent les Noirs, c'est dans l'ordre des choses en Afrique. Ils font ça depuis toujours. Par contre ce que je ne trouve pas normal, c'est que des Noirs assassinent d'autres Noirs comme vous le faites dans le bagne. » (p. 164)

7 Comment des prisonniers, soumis à un ordre normatif hyper-contraignant, développent-ils un sens de la normalité qui leur permet de survivre? La question, soulevée par les analyses classiques de Michel Foucault, a donné lieu récemment à de belles ethnographies ${ }^{2}$. Le témoignage littéraire de Roland Vilella fournit aux anthropologues des matériaux précieux, et apparemment véridiques, pour une réflexion générale sur la condition carcérale. Le titre pose une question qui reste à explorer : si une prison peut être décrite comme une «sentinelle » où la violence des relations sociales est amplifiée au point de lancer des signaux d'alerte sur son caractère insoutenable, que révèle-t-elle des logiques étatiques et juridiques qui sont censées canaliser cette violence, et qui, trop souvent, à Madagascar ou ailleurs, ne font que l'intensifier? 


\section{NOTES}

1. On retiendra les titres suivants qui ont fait date : Jean Malaurie, Les Derniers Rois de Thulé, 1955 ; Claude Lévi-Strauss, Tristes Tropiques, 1955 ; Georges Balandier, Afrique ambiguë, 1957 ; Georges Condominas, L'Exotique est quotidien: Sar Luk, Vietnam central. 1965 ; Jacques Soustelle, Les Quatre Soleils : souvenirs et réflexions d'un ethnologue au Mexique, 1967 ; Pierre Clastres, Chronique des Indiens Guayaki: ce que savent les Aché, chasseurs nomades du Paraguay, 1972 ; Pierre-Jakez Hélias, Le Cheval d'orgueil, 1975 ; Jacques Lacarrière, L'Été grec: une Grèce quotidienne de 4000 ans, 1975 ; Éric de Rosny, Les Yeux de ma chèvre: sur les pas des maîtres de la nuit en pays douala (Cameroun), 1981; Philippe Descola, Les Lances du crépuscule : relations Jivaros, Haute-Amazonie, 1993 ; Patrick Declerck, Les Naufragés: avec les clochards de Paris, 2001; Barbara Glowczewski, Rêves en colère: avec les Aborigènes australiens, 2004 ; Davi Kopenawa et Bruce Albert, La Chute du ciel : paroles d'un chaman yanomani, 2010. Sur l'ensemble de la collection, voir Pierre Aurégan, Des récits et des hommes: "Terre humaine ", un autre regard sur les sciences de l'homme. Paris, Pocket, 2004.

2. Voir Michel Foucault, Surveiller et punir : naissance de la prison. Paris, Gallimard, 1975 ; Adam Reed, Papua New Guinea's Last Place: Experiences of Constraint in a Postcolonial Prison. New York, Berghahn Books, 2003 ; Manuela Cunha, "The Ethnography of Prisons and Penal Confinement ", Annual Review of Anthropology 43 : 217-233 ; Didier Fassin, L'Ombre du monde : une anthropologie de la condition carcérale. Paris, Seuil, 2015.

\section{AUTEURS}

\section{FRÉDÉRIC KECK}

Frederic.KECK@quaibranly.fr 